\title{
REFORMAS EDUCACIONAIS E AVALIAÇÃO: MECANISMOS DE REGULAÇÃO NA ESCOLA
}

SONIA MARIA DUARTE GREGO

\section{RESUMO}

A preocupação central foi investigar as formas e racionalidades implícitas de regulação social/autonomia dos processos de gestão da aprendizagem, historicamente estabelecidas nas reformas educacionais de 1971 até 1982, via diretrizes de avaliação do rendimento escolar, no Estado de São Paulo. Utiliza-se abordagem sócio-histórica, tendo como fonte primária os discursos e documentos oficiais e como fontes secundárias os trabalhos e pesquisas sobre avaliação e trabatho docente. Tomam-se como categorias centrais a continuidade e ruptura nos padrões e mecanismos de regulação social/autonomia do trabalho educativo. Os resultados contribuem para esclarecer como as politicas educacionais, instituídas em contextos de reprodução/ transformação social, condicionam a gestão dos processos educativos no interior da escola.

PALAVRAS-CHAVE AVALIAÇÃO DA APRENDIZAGEM • REFORMA DO ENSINO - TRABALHO DOCENTE • GESTÃO. 


\title{
RESUMEN
}

La preocupación central fue investigar las formas y racionalidades implícitas de regulación social/autonomía de los procesos de gestión del aprendizaje, históricamente establecidas en las reformas educativas de 1971 a 2002, por medio de las directrices de evaluación del rendimiento escolar, en el estado de San Pablo. Se utiliza un abordaje socio-histórico, teniendo como fuente primaria los discursos $y$ documentos oficiales y como fuentes secundarias los trabajos e investigaciones sobre evaluación y trabajo docente. Se toman como categorías centrales la continuidad y la ruptura en los patrones y mecanismos de regulación social/autonomía del trabajo educativo. Los resultados contribuyen a aclarar como las políticas educativas instituidas en contextos de reproducción/transformación social, condicionan la gestión de los procesos educativos en el interior de la escuela.

\section{PALABRAS CLAVE AVALIACIÓN DE LA APRENDIZAJE・ REFORMA DE LA EDUCACIÓN・TRABAJO DEL PROFESOR • GESTIÓN.}

\begin{abstract}
Our main concern was to investigate the forms and rationalities implicit in the social regulation/autonomy of the management processes of learning, historically established in the 1971 through 2002 educational reforms, via assessment guidelines of school performance in the state of São Paulo. We used a socio-historical approach, relying on speeches and official documents as our primary source and on studies and research work about teacher assessment and performance as secondary sources. As central categories we considered continuity and rupture in the patterns and mechanisms of social regulation/autonomy of educational work. The results help to clarify how educational policies, instituted in contexts of social reproduction/transformation, influence the management of educational processes within the school.
\end{abstract}




\section{INTRODUÇÃO}

A avaliação do rendimento escolar, historicamente, vem sendo o foco de debates e conflitos no contexto das políticas de educação no Brasil. A análise das circunstâncias e dos discursos, presentes nas sucessivas reformas, a partir da década de 1970, permite mostrar os personagens principais desse conflito: o governo, de um lado, com sua gestão nas mudanças educacionais e, de outro, os professores, apontados, em função da sistemática da avaliação adotada, como responsáveis pelo fracasso escolar e pela exclusão de significativa parcela da população do direito básico à educação.

Implícita, ainda, nas sucessivas reformas, encontra-se a ideia de que as mudanças propostas, contrapondo-se à lógica e às práticas dos professores, possibilitarão eliminar os altos índices de evasão e repetência, garantir uma escola de qualidade e a rentabilidade do sistema (GREGO, 2003).

Especificamente, é a prática avaliativa dos professores, pela forma criada de gestão do processo educativo, que tem sido posta em questão, considerada como "de resistência à aprovação de estudantes” (PARO, 2000, p. 273). 
Esse conflito e essa lógica foram ganhando espaço e especificidades no contexto das reformas educacionais do Estado de São Paulo, nas quais a avaliação foi assumindo, gradativamente, o papel central na definição das políticas educacionais.

Em contrapartida, para os profissionais da educação que militam nas escolas públicas, conforme evidenciado em estudos e pesquisas, as reformas educacionais geralmente, incluindo as reformas nos processos de avaliação, influenciam a qualidade da educação, relativizando o domínio efetivo de competências e habilidades dos alunos, e o privilegiamento do "tempo tarefeiro" em detrimento do "tempo de construção do conhecimento" e do processo de intensificação do trabalho docente. As reformas também apresentam contradições de natureza conceitual e teórico-metodológica em decorrência das diferentes perspectivas teóricas que orientam as modalidades, estratégias e procedimentos de avaliação, bem como as modalidades de regulação das aprendizagens dos alunos e de recuperação de estudos em um regime de progressão continuada por meio de um sistema de ciclos, que passam a ser adotados no cotidiano da escola (MACHADO, GREGO-VEIGA, 1986/1987; AFONSO, 1998; ABRAMOWICZ, 1999; ARENA, 1999; GARITA, 1999, 2010; FREITAS, 2003; OLIVEIRA, 2008; HIPOLITO, VIEIRA, PIZZI, 2009).

A persistência nos procedimentos de avaliação contraditórios, evidenciando um descompasso entre o normatizado e o efetivado nas escolas, e a consciência de que diferentes modalidades de avaliação trazem implícitas diferentes concepções de natureza epistemológica, político-social e teórica, colocam a necessidade de se identificar a(s) lógica(s) que orienta(m) as diferentes propostas de avaliação, objeto de normatização no Estado de São Paulo, e de analisar como esses atos normativos intervêm historicamente nos processos de gestão do ensino em sala de aula e de qualificação/desqualificação do trabalho docente no espaço da escolarização.

\section{METODOLOGIA}

A pesquisa envolveu dois passos metodológicos. O primeiro caracteriza-se na análise documental, considerando-se as regras e os padrões dos textos como uma prática social, com um 
interesse nas condições históricas dentro das quais predomina um determinado discurso, buscando apreender as relações entre conhecimento e formas de regulação social, como proposto por Popkewitz (1997).

Como fontes primárias, foram analisados os discursos e os documentos oficiais dos órgãos do governo federal, do governo do Estado de São Paulo e das fontes históricas de referência. E como fontes secundárias, os estudos e as pesquisas sobre avaliação da aprendizagem, avaliação como instrumento de gestão e trabalho docente.

O segundo passo envolveu análise crítica, em uma abordagem sócio-histórica, tomando como categoria central o trabalho docente e tendo como eixos de análise a continuidade e a ruptura nos padrões e mecanismos de regulação social/autonomia, bem como nos padrões de dependência/independência do trabalho docente, via normatização dos processos de avaliação no sistema educacional do Estado de São Paulo.

A análise se centrará em três períodos distintos: de 1971 a 1982, de 1983 a 1994 e de 1995 a 2002. Essa periodização segue as mudanças de rumos e de orientações político-econômicas no Estado de São Paulo. Em cada um desses períodos serão pontuadas apenas as mudanças de maior impacto para a prática avaliativa dos professores, com reflexos na gestão do processo educativo e aquelas que mais influenciaram as relações de poder no interior da escola, e entre essa e os órgãos superiores.

\section{A REGULAÇÃO DA AVALIAÇÃO \\ NA DITADURA MILITAR E O}

\section{TRABALHO DOCENTE - DE 1971 A 1982}

A política educacional da década de 1970, gestada na época da ditadura militar, representou uma ruptura com os padrões tradicionais ao redefinir as bases estruturais e as relações instrumentais da escolarização segundo os padrões estruturais de reordenamento do Estado.

No âmbito da Lei de Diretrizes e Bases da Educação Nacional (LDBEN) (BRASIL, 1971), expressão mais visível, à época, da nova política educacional de $1^{\circ}$ e $2^{\circ}$ graus, pela primeira 
vez a avaliação do rendimento escolar situa-se como elemento básico de regulação social do trabalho educativo. Como explicitado no documento do Grupo de Trabalho da Reforma e na Exposição de Motivos da LDBEN, das três fases do ato docente-discente - planejamento, execução e verificação -, somente a verificação comporta e exige alguma disciplina.

Para compreendermos a forma como esse disciplinamento imposto afeta o trabalho docente, é necessário situá-lo no contexto da reforma educacional.

Em uma maior proporção, tratava-se, no dizer de Freitag (1979, p. 126), de "garantir à educação sua funcionalidade múltipla no capitalismo dependente em que se insere o Brasil”.

Sob o impacto de medidas restritivas, a crise do sistema educacional, acirrada com as greves dos estudantes e a demanda social por educação, levou a medidas práticas no curto prazo, que serviram

[...] de justificativa para uma série de acordos entre O MEC

e seus órgãos e a Agency for International Development (AID) [...] pelo qual o MEC entregou a reorganização do sistema educacional brasileiro aos técnicos oferecidos pela AID. (ROMANELLI, 1978, p. 196-197)

No diagnóstico da AID, as principais causas do fracasso das escolas eram a ausência de planificação da educação e o despreparo dos agentes educativos.

Embasada em modelos técnico-científicos exógenos, de racionalidade instrumental na acepção de Popkewitz (1997), a ênfase é colocada na expansão quantitativa do sistema, o que torna natural a "obtenção de maior rendimento da rede escolar existente, com a menor aplicação de recursos, com base em estudos de 'rentabilidade' do sistema” (ROMANELLI, 1978, p. 204).

É nesse processo de planificação técnico-científica, em que qualidade passa a ser entendida como quantidade, eficiência e eficácia, que a avaliação do rendimento escolar vai assumir papel preponderante como mecanismo de controle da qualidade de ensino e engendrar práticas estruturais e socializadoras do pensar e do fazer docente.

Se no âmbito geral a função social atribuída à avaliação é de fornecer bases para o planejamento e ajuste de políticas educacionais e práticas educativas, assumindo especificamente 
funções diagnóstica, formativa e somativa (classificatória), é na instância estadual que se configura a inserção da nova sistemática de avaliação no trabalho pedagógico da escola e do professor.

De acordo com documento distribuído aos professores à época da implantação da reforma (SÃO PAULO, s/d, p. 13-14), a:

[...] avaliação envolve [...] avaliação diagnóstica, que se destina a revelar as condições de entrada do aluno, e permitir o ajuste do planejamento das atividades; avaliação formativa, (que) informa [...] se há necessidade de retificação, enriquecimento ou integração da aprendizagem; somativa: informando da efetividade do processo de instrução e da situação do aluno.

Nessas funções a avaliação se insinua na totalidade do ato educativo, ao mesmo tempo em que redefine as formas de concepção e de execução do trabalho docente no interior da escola, com a adoção do modelo pedagógico de orientação positivista, que, redefinindo a relação teoria e prática no trabalho docente a partir de critérios de racionalidade tecnológica, se coloca em contradição com os referenciais teóricos a orientar os programas de formação de professores, na época, com as condições estruturais e com a cultura avaliativa da escola.

De uma visão filosófica da prática educativa, em que o papel da teoria educacional era encorajar os professores para desenvolver uma visão compreensiva de seu papel como educadores, engajando-os em um processo de reflexão filosófica, o trabalho docente é submetido a uma visão técnica, na qual a função da teoria é orientar a prática providenciando um corpo de conhecimentos científicos em termos dos quais a atividade educacional poderia ser avaliada e práticas novas e mais efetivas seriam derivadas (CARR, KEMMIS, 1993).

Nesta nova perspectiva, o professor é expropriado do poder de influenciar, por deliberação prática e intervenção prudente, a ação educativa em sala de aula, sendo o trabalho docente subordinado a uma visão técnica, que vê o ensino e os comportamentos de aprendizagem como elementos em um sistema que pode ser controlado externamente, e através do qual os objetivos preestabelecidos podem ser atingidos com sucesso, mediante treinamento dos professores para 
seguirem um conjunto sequenciado de procedimentos ou técnicas de ensino cientificamente comprovados.

O professor, considerado despreparado para aderir à nova concepção, necessitava de treinamento para que compreendesse, aceitasse a proposta de orientação tecnicista, e se instrumentalizasse para aplicá-la, o que foi realizado através de programas de educação continuada, visando entre outras técnicas, a capacitá-lo na especificação de objetivos comportamentais, porque é pela subordinação da avaliação aos escopos curriculares mínimos que se exerce toda a pressão modeladora dos sistemas sobre o trabalho docente e "de controle, de valorização dos indivíduos frente à sociedade” (SACRISTÁN, 1998).

Não há espaço, nessa agenda política, para o saber profissional do professor como "conhecimento situado e construído na interação social e sobre a singularidade das situações sociais" (CARIA, 2006, p. 134) e, especialmente, como "atividade profissional complexa e de alto nível, que exige conhecimentos e competências em vários campos" (TARDIF, LESSARD, 2008, p. 9).

Nesse sentido, a reforma, como normatização do processo avaliativo, contribuiu para a desqualificação do trabalho docente, na medida em que nega seu saber e seu fazer, colocando em suspeição sua formação profissional, ao subordinar os processos didático-pedagógicos da educação fundamental à deliberação e ação de agentes externos. A desqualificação da escola foi negada como espaço formativo e de deliberação do modelo pedagógico a ser adotado, e prejudicada em sua forma de funcionamento e organização, que prevalece com uma "estrutura seriada estanque, com condições e segundo valores e rituais que nem sempre correspondem à intencionalidade declarada no discurso oficial" (SOUZA, 1986, p. 193).

Sob orientação dos atos normativos, alteram-se as formas de relacionamento e a hierarquia de poder no interior da escola, pela ampliação das competências dos especialistas, devendo os instrumentos de avaliação elaborados pelos professores, não especialistas, serem submetidos à aprovação "do Coordenador Pedagógico ou, na inexistência deste, do Diretor de Escola" (SÃO PAULO, 1977, p. 5-6, 18).

No conjunto, os atos normativos implicaram na perda de autonomia do trabalho do professor, afetando sua própria 
identidade funcional. Não se pode ignorar, como afirma Sacristán (1998, p. 329), que:

[...] outra consequência importante da ampliação do objeto da avaliação, com a consequente complexidade técnica, reside na potencial divisão da função educativa e certa desprofissionalização dos professores ao se tratar de uma tecnificação de modelos que escapa de sua competência, exigindo a atuação "de novos profissionais não docentes".

Em específico, a reforma da década de 1970, ao superdimensionar o espaço e o papel da avaliação, transformando-a na pedra angular da instituição escolar, passa a depositar nesta, por um processo de redução dos problemas teóricos da educação ao âmbito técnico da avaliação, como argumenta Barriga (1999, p. 56, 60), a expectativa de resolução de problemas de diversas ordens que "podem ser sociológicos, políticos, pedagógicos e técnicos (e, em decorrência) realiza uma inversão entre os problemas de método e os de rendimento" que altera as relações pedagógicas. Na prática docente anterior à reforma, sustentada nos princípios da pedagogia tradicional, a avaliação estava inegavelmente ligada ao método expositivo, que previa a realização de atividades e exercícios de aplicação e de generalização do que se aprendeu como etapas metodológicas do processo de ensino e aprendizagem e, em caso de o aluno não aprender, fazia-se a revisão do método. Na visão instrumental da reforma, a avaliação passa a ser o instrumento central do trabalho docente, assumindo não só as funções:

[...] que dizem respeito à melhoria dos processos de aprendizagem: a seleção, a certificação e a responsabilização; a promoção da motivação dos sujeitos e o desenvolvimento de uma consciência mais precisa sobre os processos sociais e educacionais; (mas) a função que relaciona a avaliação com o exercício da autoridade, sobretudo no contexto organizacional (como também) as funções simbólicas, de controlo social e de legitimação política. (AFONSO, 1998, p. 31)

Desse modo, houve uma "inversão de problemas pedagógicos a problemas de rendimento (o que) perverteu a relação pedagógica ao centrar os esforços dos estudantes e docentes apenas na certificação" (AFONSO, 1998, p. 31). 
Não se pode concluir, no entanto, que a reforma dos anos 1970 tenha fracassado totalmente, se analisado na ótica dos objetivos da educação no âmbito da reforma do Estado. Há de se considerar, entre outros fatores, que a expansão da rede escolar, segundo as exigências da demanda social de educação, poderia comprometer em parte a política econômica do governo. Daí a manutenção de duas lógicas avaliativas: a classificatória (mas que envolvia um acompanhamento metódico da aprendizagem dos alunos) e a criterial, centrada em objetivos preestabelecidos, com ênfase em provas e testes. E, essa manutenção certamente teve um papel na socialização do trabalho docente e na moldagem da identidade do professor na ótica instrumental e mercantil.

\section{A NORMATIZAÇÃO DA AVALIAÇÃO NO PERÍODO DE ABERTURA DEMOCRÁTICA E O TRABALHO DOCENTE - 1983-1994}

No contexto de globalização da economia e de abertura democrática no país, defrontam-se no cenário nacional duas tendências político-ideológicas quanto à forma de pensar a educação: uma voltada para uma educação democrática e para a formação da cidadania, e outra, de orientação neoliberal, que vê a escola básica de uma "lógica instrumental de formação, de qualificação do trabalhador" (OLIVEIRA, 1996, p. 61).

A convivência dessas duas tendências representa o terreno para a emergência de reformas pontuais e fragmentadoras do trabalho docente no âmbito do sistema.

A primeira reforma pontual ocorre com a instituição do $\mathrm{CB}$ (Ciclo Básico), caracterizado por um conjunto de atos normativos, com o objetivo explícito de eliminar a possibilidade de reprovação do aluno ao final do $1^{\circ}$ ano escolar. Analisando o projeto político do CB, Duran, Alves e Palma Filho (2005, p. 92) explicam que:

\footnotetext{
A implantação do ciclo básico (CB), no início dos anos 80, foi uma medida de impacto na rede pública de ensino do Estado de São Paulo, que transformou as antigas $1^{a}$ e $2^{\underline{a}}$ séries do então primeiro grau em um continuum durante 0 qual o aluno realizaria o processo de aprendizagem sem interrupção, eliminando-se as reprovações no primeiro ano de
} 
escolaridade. A medida procurava combater um dos mais graves problemas do ensino fundamental em todo o país: inacreditáveis índices de reprovação e evasão de alunos já em seu primeiro ano de escola.

A implantação do CB, que tinha como "única medida obrigatória que as crianças não deveriam ser reprovadas" (SILVA, DAVIS, 1994, p. 37), representou avanços na mobilização para a participação e ações ao resgate da autonomia de dirigentes e professores, bem como no sentido de uma avaliação centrada no processo de desenvolvimento do aluno, e gerou conflitos e reações de desconforto e de resistências no interior da escola, mas também em diversos segmentos conservadores da sociedade, resistências alimentadas, à época, pelas manchetes negativas nos principais jornais do Estado de São Paulo (NÉBIAS, 1990; DURAN, ALVES, PALMA FILHO, 2005).

As resistências mais significativas:

[...] articularam-se em torno de três questões: o caráter arbitrário da implantação, o perigo de rebaixamento da qualidade de ensino e a questão da avaliação do rendimento dos alunos. [...] A própria sistemática da implantação pode ter contribuído para fomentar a resistência à desseriação entre os profissionais da rede pública estadual: foi uma decisão central, efetivada por decreto, daí a crítica à arbitrariedade da medida. (DURAN, ALVES, PALMA FILHO, 2005, p. 94)

Nébias (1990, p. 114) investiga a implantação do CB enquanto a expressão de um plano de política educacional de um governo democrático evidencia que "o Decreto não foi reconhecido como deles e por isso se sentiram logrados, tornando-se resistentes". Embora fosse envolvida toda a rede de ensino na discussão sobre os problemas de ensino, em especial os ligados à evasão e repetência, fato avaliado positivamente por diretores, professores e entidades de classe, a maioria entendeu que suas vozes não foram ouvidas e que sequer o governo soube responder a suas propostas.

Mas, se a participação dos professores não foi valorizada na implantação do $\mathrm{CB}$, na discussão do novo estatuto do magistério, toda a rede de ensino foi ouvida e suas propostas e sugestões, respeitadas. Este foi também o período em que se 
possibilitou maior autonomia ao trabalho docente, pois durante o processo de implantação do CB houve um empenho especial da Secretaria de Educação em discutir exaustivamente a proposta com todos os professores envolvidos, o que

$[\ldots .$.$] derrubou algumas resistências [...] mas questões fundamen-$ tais sobre alfabetização, avaliação, promoção, remanejamento le grupo de apoio suplementar permaneceram pouco esclarecidas. (NÉBIAS, 1990, p. 118-119)

As duas outras questões estavam diretamente relacionadas à nova sistemática de avaliação, pois a visão dos que temiam o rebaixamento do ensino era a de estar eliminando a avaliação e implantando a aprovação automática.

Na proposta do ciclo básico, o acompanhamento do desempenho do aluno, de sua melhora no processo de alfabetização e o respeito ao ritmo de seu desenvolvimento eram elementos centrais da nova proposta de avaliação. Para registrar as melhorias na aprendizagem dos alunos, eram usadas fichas de registro de desempenho e progresso do aluno, como também observação, e não mais provas e exercícios padronizados. O que se propunha era uma avaliação formativa na qual se privilegia mais:

[...] o modo de agir do aluno do que os resultados. "Procura-se, sobretudo, compreender (o seu) funcionamento cognitivo [...] perante a tarefa proposta". (Um) tipo de avaliação [...] mais flexível e aberto, menos "mecanicista" [...] implicando muito mais o aluno [...] a trajetória seguida pelo aluno [...] uma atividade simultaneamente mais complexa e individualizada e, sobretudo, mais autônoma que uma avaliação pontual [...] processo em que estão implicados alunos e professores e que residem na estruturação da situação da aprendizagem. (ABRECHT, 1994, p. 41-47)

Mas os professores questionavam: O que e como avaliar? Eles cobravam da Secretaria da Educação a determinação dos critérios de avaliação e de seu registro, elemento central da proposta de avaliação mecanicista do período anterior, que exigia, não a ficha, mas a atribuição de um critério de qualificação (escala de A até E), que continuou oficialmente em vigor para toda a rede de ensino da $3^{\mathrm{a}}$ até a $8^{\mathrm{a}}$ série e que levou muitas secretarias de escola a exigir que os professores do $\mathrm{CB}$ 
atribuíssem também um critério a seus alunos para efeito de registro escolar (SÃO PAULO, 1977, p. 3, 11).

O conflito entre as duas lógicas avaliativas - a proposta pela reforma e a que continuava em vigor para as séries subsequentes da escolarização, segundo determinações legais instituídas no regime militar (p. 19 ) - refletiu-se:

[...] tanto no trabalho administrativo das escolas [...] como na prática avaliativa dos professores, contribuindo para instalar-se uma desarticulação entre a teoria que embasava a nova proposta e a cultura e a prática avaliativa da escola. (GARITA, 1999, p. 79)

O emblemático é que mesmo em um governo que assume um compromisso com a democratização do ensino ocorre

[...] uma forma de regulamentação social, na medida em que é conferido status ao conhecimento especializado. [...] O âmbito da responsabilidade e da autonomia é limitado aos interesses técnicos, com questões de poder escondidas por trás de uma retórica de progresso. (POPKEWITZ, 1997, p. 182)

Novo governo, novas reformas a embutirem processos tanto de ruptura como de continuidade nas práticas avaliativa e pedagógica dos professores.

Ruptura, pois com a mudança de governo se implanta o Projeto Educacional Escola-Padrão, que atribuiu autonomia didática e administrativa a um conjunto de escolas na construção de seus projetos pedagógicos, ainda que instituindo, através de atos normativos, um modelo político-pedagógico que implicou a adoção de uma concepção e uma proposta de avaliação de orientação construtivista.

Continuidade, seja por manter inalterada a legislação da década de 1970, perpetuando o conflito entre duas lógicas avaliativas, desestabilizando o pedagógico na relação com o burocrático; seja pela exclusão da maioria das escolas do processo inovador; seja por reproduzir a lógica da reforma que "induz uma relação centralizadora do centro com a periferia [...] alimentando a ilusão da possibilidade de produzir tecnologias de mudança 'prontas a usar' para mudar pessoas e organizações” (CANÁRIO, 1999, p. 276).

É desse governo, ainda, o ato que "normatiza os pedidos de reconsideração e recursos relativos aos resultados finais 
de avaliação de alunos do sistema de ensino de $1^{\circ}$ e $2^{\circ}$ graus" (SÃO PAULO, 1991, p. 165).

Ao atribuir poder aos supervisores para encaminhar representação ao Delegado de Ensino quando constatasse a retenção do aluno, é criada, na prática, uma poderosa instância de avaliação externa à escola. Alteram-se, dessa forma, as relações de poder entre a escola e as instâncias superiores, uma vez que o poder que o professor possui advém da avaliação (AFONSO, 1991).

\section{A REGULAÇÃO DA AVALIAÇÃO NO GOVERNO NEOLIBERAL E O TRABALHO DOCENTE - DE 1995 A 2002}

É no processo de modernização e racionalização do novo governo neoliberal, no qual a educação passa a ser considerada como setor de serviços não exclusivos do Estado e qualidade educacional a ser entendida como custo-benefício, que a política educacional do Estado de São Paulo toma como eixos a "ineficiência" e a "ineficácia do sistema", e a avaliação se torna o principal elemento na definição das políticas educacionais (SÃO PAULO, 1995).

Novas rupturas, pois a preocupação com os baixos "índices de desempenho, e com o mau aproveitamento racional dos recursos [...] e a falta de mecanismos de controle" (SÃO PAULO, 1995, p. 298-299) leva à introdução de medidas de grande impacto nas escolas como o Programa de Reorganização das Escolas da Rede Pública e à edição de um "pacote" de reformas na área da avaliação, envolvendo tanto a avaliação da aprendizagem dos alunos como a avaliação institucional (interna e externa) e a extinção da Escola-Padrão.

No conjunto, essas medidas se constituíram, efetivamente, em um fator de socialização e regulação do pensamento e da prática avaliativa do professor, visto que acabaram por retirar-lhe todo o poder no processo de avaliação, num contexto em que é proibido repetir.

Essa palavra de ordem ganha gradativamente expressão legal em atos normativos sobre recuperação paralela e nas férias, sobre classes de aceleração, remanejamento e reclassificação 
de alunos, procedimentos paralelos e intensivos de reforço, culminando com a progressão continuada em sistema de ciclos (SÃO PAULO, 1997), entendida como fluxo contínuo.

O monitoramento do trabalho docente, a classificação das escolas e, inclusive, a promoção do aluno ao final dos ciclos são efetivados pelo órgão superior através de mecanismos de avaliação institucional, de natureza competitiva e classificatória, que se colocam em tensão e em contradição com a avaliação exigida no interior da escola, que se propõe formativa, mais interativa e dialógica.

A avaliação assume a função de responsabilização social, "uma forma tecnocrática de valorar e um procedimento burocrático de exigir o cumprimento de obrigações" (SOBRINHO, 2002, p. 29) com a implantação do Sistema de Avaliação de Rendimento Escolar do Estado de São Paulo (Saresp), que tinha entre seus principais objetivos, além da monitoração do sistema para orientar as políticas:

[...] possibilitar às escolas, a partir de análises sobre o desempenho alcançado por seus alunos em diferentes disciplinas, implementar uma série de ações que assegurem a aprendizagem ao longo da trajetória escolar. Daí a importância da divulgação (confidencialmente aos professores) dos resultados obtidos pelos estudantes nas provas aplicadas ano a ano. (SÃO PAULO, 1999, p. 5)

No entanto, em 2001, a Secretaria da Educação introduziu uma mudança casuística nas finalidades da avaliação do Saresp, que passou a ter como objetivo central "aferir junto aos alunos as condições para continuidade de seus estudos no Ciclo II ou no Ensino Médio, uma vez que seus resultados se constituirão em indicador essencial para a promoção do aluno" (SÃO PAULO, 2001, p. 3, grifos nossos). Assume, assim, o governo central, via avaliação, funções pedagógicas legal e institucionalmente atribuídas às escolas, passando a ser o único referencial para decidir o encaminhamento dos alunos, determinando sua possível promoção, recuperação de férias ou retenção.

Esse monitoramento passou a ser exercido, ainda, via Deliberação do Conselho Estadual de Educação, ao exigir do professor a adoção de um conjunto de novas práticas avaliativas e elaboração de um grande número de documentos e registros 
sobre o desempenho do aluno, sobre atividades de recuperação e de acompanhamento das dificuldades dos alunos a serem, inclusive, comunicadas aos pais (SÃO PAULO, 1996), cuja elaboração implica a adoção de uma engenharia da instrução, geralmente incompatível com as condições estruturais da escola e, em específico, com a modalidade de avaliação proposta para toda a rede de ensino.

Outra mudança de destaque é que os resultados dos alunos, associados a taxas de abandono e evasão, passaram a servir para classificação das escolas. Em função desses indicadores "chegou-se à organização de cinco grandes grupos de escolas denominadas azul, verde, amarelo, laranja e vermelho" (SÃO PAULO, 2001, p. 6). De acordo com a classificação, as escolas foram diferenciadas no tocante à liberação de recursos financeiros, às recompensas recebidas e a programas de qualificação atribuídos aos agentes educativos.

Essa função atribuída, à época, ao Saresp contraria não só a LDB (Lei n. 9394/96), como também os documentos que a normatizam no âmbito estadual, seja em relação aos princípios de gestão democrática da escola, seja em relação ao estabelecido para o processo de avaliação do rendimento escolar dos alunos. Desconhece e atropela, ainda, princípios estabelecidos nas Normas Regimentais Básicas para as Escolas Estaduais Paulistas, a qual, em atendimento à lei maior, define em seu Titulo II - Da Gestão Democrática que:

[...] a gestão democrática tem por finalidade possibilitar à escola maior grau de autonomia (art. 7ㅇ); valorização da escola enquanto espaço privilegiado da execução do processo educacional (Art. 9o inciso V); capacidade de cada escola coletivamente formular, implementar e avaliar sua proposta pedagógica e seu plano de gestão. (SÃo PAULO, 1998, p. 187)

Impõe considerar, ainda, que neste período as normas para elaboração do Regimento das Escolas apresentaram-se tão detalhadas que o mesmo foi visto como um "modelo" pronto e acabado, restando pouco espaço ao coletivo da escola para assumir-se como sujeito da própria prática para elaborar seu próprio Regimento, conforme estabelecido na Lei de Diretrizes e Bases da Educação Nacional - LDBEN (BRASIL, 1996), interferindo na construção de um processo de participação dos agentes 
educativos como postura política de intervenção na realidade, no qual pressupõe que os agentes sociais da prática educativa tenham: a) consciência do direito e dever de intervir; b) capacidade (e autonomia) para atuar no processo; c) organização para que sua participação seja efetiva (ARGUMEDO, 1985, p. 48).

\section{REFLETINDO SOBRE O IMPACTO \\ DAS PROPOSTAS DE AVALIAÇÃO DO GOVERNO NO TRABALHO DOCENTE}

A imposição desses modelos tecnocráticos e de responsabilidade social submete, na prática, o trabalho docente a técnicas de administração social, no sentido atribuído por Popkewitz (1997), sob condições que, se não inviabilizam totalmente, certamente restringem as possibilidades de qualificação e de reflexão do professor sobre sua própria prática ao subtrair da escola e dos docentes a gestão do processo educativo e de formação dos alunos.

O problema a ressaltar é que a redução da ênfase na avaliação formal do aluno, em sala de aula, e seu deslocamento para processos informais de avaliação:

[...] bem como a ênfase maior em processos mais gerais de avaliação de sistema, fazem com que a qualidade seja objeto de medidas de desempenho como eficiência do sistema de ensino e não como igualdade de resultados dos alunos matriculados nas escolas desse sistema. (FREITAS, 2007, p. 974)

Além disso, o caráter impositivo e a descontextualização, que têm cercado essas medidas, e os esforços para preparar os professores para implementá-las através de programas de educação continuada terceirizada, o que induz a um formalismo pedagógico, levam a se questionar os reais interesses que as orientam.

No entanto, em que pese os descaminhos das políticas atuais de avaliação, é importante ressaltar, como lembra Gatti (2007, p. 6), que:

[...] este problema não tira o mérito das intenções dos implementadores dessas avaliações. Na verdade, esses processos avaliativos acabam por apontar fortemente para a necessidade de uma ampla discussão sobre o currículo escolar na 
educação básica, na busca de melhor orientação de gestores, escolas e professores sobre os conteúdos principais esperados que a escola trabalhe com os alunos. Aponta, também, para a necessidade de aperfeiçoamento do processo avaliativo. Isto porque consideramos importante esse tipo de avaliação para definição, redefinição de políticas, propostas, atuação dos gestores em diferentes níveis, atuação das escolas e dos professores, bem como para informação dos pais e da comunidade e suas possíveis atuações.

O que se coloca em questão é que o processo de socialização e de regulação da prática avaliativa exercido pelas reformas, a resistência dos professores, a não provisão de condições estruturais no interior das escolas, a persistência de práticas de avaliação classificatória, a desconsideração de fatores de ordem econômica, social e cultural que atuam sobre o aluno, a tendência atual de se exigir dos estudantes das classes privilegiadas os objetivos proclamados e dos das classes trabalhadoras “o mínimo do mínimo”, a partir do ponto em que se encontra, vêm contribuindo para manter intactos os mecanismos de seletividade e exclusão, se não mais escolar, pessoal e profissional futuros já denunciados por Barbier (1990).

No conjunto, as políticas propostas pelos diferentes grupos que se sucederam no governo estadual acabaram gerando resistências e confusão no interior da escola, criando, em vários aspectos, situações constrangedoras ao trabalho docente, o que acabou contribuindo ainda mais, contrariamente ao proclamado, para sua desqualificação, bem como para o esvaziamento da autoridade do professor e da escola no sistema educacional do Estado.

Essas mudanças, postas às escolas no âmbito das reformas educacionais do Estado, são um importante indicador de como a avaliação vem sendo utilizada como instrumento de regulação do trabalho docente, dos processos de gestão escolar e de socialização de práticas.

Os efeitos e reações negativos desse processo de orientação tecnológica, tanto política como tecnicamente, devem levar a um repensar da avaliação externa no Estado de São Paulo, notadamente na eliminação das rotulações e em mudanças no uso dos resultados. 
O que se propõe é que a avaliação nos três níveis (sistema, escola e sala de aula) se torne mais democrática, dialógica e solidária, no sentido de torná-la mais focada na qualidade da formação do aluno e na qualificação dos processos de gestão escolar e do trabalho educativo, ampliando os espaços de participação de todos os sujeitos e instâncias envolvidos e/ou afetados pelo processo avaliativo. Que a avaliação se torne um instrumento a serviço da melhoria da qualidade do ensino, como propõe Landsheere (1997), e se assente na valorização da escola, dos professores, dos alunos e dos princípios de gestão democrática proclamados. E que, como propõe Afonso (1991, p. 44), a avaliação na e da escola se estruture "na base de relações de reciprocidade [...] na valorização do conhecimento - emancipação, na validação intersubjetiva”.

\section{REFERÊNCIAS}

ABRAMOWICZ, Mere. Avaliação e progressão continuada: subsídios para uma reflexão. In: BICUDO, Maria A.V; SILVA JÚNIOR, Celestino A. A Formação do educador e a avaliação educacional. São Paulo: Unesp, 1999. v. 4. p. 155-177.

ABRECHT, R. A Avaliação formativa. Rio Tinto, Portugal: Asa, 1994. p. 175.

AFONSO, Almerindo J. O Poder de avaliar na génese de uma sociologia da avaliação. 0 professor, n. 22. Braga, Portugal: Universidade do Minho, 1991. p. 40-45.

. Políticas educativas e avaliação educacional: para uma análise sociológica da reforma educativa em Portugal (1985-1995). Braga, Portugal: Universidade do Minho, 1998.

ARENA, Dagoberto B. Projeto pedagógico e avaliação: as tensões no interior da escola. In: BICUDO, Maria A. V.; SILVA JÚNIOR, Celestino A. A Formação do educador e a avaliação educacional. São Paulo: Unesp, 1999. v. 1, p. 77-89.

ARGUMEDO, Manuel. Elaboração curricular na educação participante. In: WERTHEIN, Jorge Y.; ARGUMEDO, Manuel. Educação e participação. Rio de Janeiro: Philobiblion; Brasília: IICA, 1985. p. 41-77.

BARBIER, Jean-Marie. A Avaliação em formação. Porto: Afrontamento, 1990. 286 p.

BARRIGA, Ángel D. Uma polêmica em relação ao exame. In: ESTEBAN, M. T. (Org.) Avaliação: uma prática em busca de novos sentidos. Rio de Janeiro: DP\&A, 1999. p. 51-82.

BRASIL. Câmara dos Deputados. Lei n. 9394 - Lei de Diretrizes e Bases da Educação Nacional. Brasília, 1996. 
. Lei n. 5692. 11 de agosto de 1971. Fixa as diretrizes e bases para o ensino de $1^{\circ}$ e $2^{\circ}$ graus e dá outras providências. In: São Paulo (Estado). Secretaria da Educação. Legislação de Ensino de 1ํo e $2^{\circ}$ graus (Federal). São Paulo: SE/CENP, v. 1, 1980. p. 403-414.

CANÁRIO, Rui. O Professor entre a reforma e a inovação. In: BICUDO, Maria Aparecida V.; SILVA JÚNIOR, Celestino A. Formação do educador e avaliação educacional: organização da escola e do trabalho pedagógico. São Paulo: Unesp, 1999. v. 3, p. 271-289.

CARIA, Telmo H. Os Saberes profissionais técnico-intelectuais nas relações entre educação, trabalho e ciência. In: TEODORO, António; TORRES, Carlos Alberto (Org.). Educação crítica e utopia: perspectivas para o século XXI. São Paulo: Cortez, 2006. p. 127-146.

CARR, Wilfred; KEMMIS, Stephen. Becoming critical: education, knowledge and action research. London; Philadelphia: The Falmer, 1993.

DURAN, Marília C. G.; ALVES; Maria L.; PALMA FILHO, João C. Vinte anos da política de ciclo básico na rede estadual paulista. Cadernos de Pesquisa, São Paulo, v. 35, n. 124, p. 83-112, jan./abr. 2005.

FREITAG, Barbara. Escola, Estado e sociedade. 3. ed. São Paulo: Cortez \& Moraes, 1979.

FREITAS, Luiz Carlos. Ciclos, seriação e avaliação: confrontos de lógicas. São Paulo: Moderna, 2003. Coleção Cotidiano Escolar.

Eliminação adiada: o ocaso das classes populares no interior da escola e a ocultação da (má) qualidade do ensino. Educação e sociedade, Campinas, v. 28 , n. 100, p. 965-987, 2007.

GARITA, Rosaly M. S. Avaliação para a formação: o cotidiano da escola e a proposta legal. 1999. p. 309. Tese (Doutorado) - Faculdade de Filosofia e Ciência, Unesp, Campus de Marília, 1999.

Os Enigmas da avaliação da aprendizagem e as políticas educacionais. In: ROSSIT, Rosana A. S.; STORANI, Karin. Avaliação nos processos educacionais. São Paulo: Unifesp, 2010. p. 99-129.

GATTI, Bernardete A. Avaliação e qualidade da educação, 2007. Disponível em: $<$ http://www.anpae.org.br/congressos_antigos/simposio2007/51.pdf $>$. Acesso em: 12 set. 2010.

GREGO, Sonia. M. D. A avaliação nas reformas educacionais do Estado de São Paulo (1982-1998): implicações para o trabalho docente. In: V SIMPÓSIO DE FILOSOFIA E CIÊNCIAS - Trabalho e conhecimento: desafios e responsabilidades da ciência, 2003, Marília - SP. Anais... Marília/SP: Unesp Marília Produções, 2003.

HIPOLITO, Álvaro M.; VIEIRA, Jarbas S.; PIZZI, Laura C. V. Reestruturação curricular e autointensificação do trabalho docente. Currículo sem fronteiras, v. 9, n. 2, p.11-112, 2009. Disponível em: <http://www.curriculosemfronteiras. org/vol9iss2articles/hypolito-vieira-pizzi.pdf>. Acesso em: 13 jul. 2010.

LANDSHEERE, Gilbert. A Pilotagem dos sistemas de educação: como garantir a qualidade de ensino? Lisboa, Portugal: Asa, 1997. 192 p. 
MACHADO, Maria J.; GREGO-VEIGA, Sonia M. Avaliação de programa de recuperação com estagiários do curso de magistério. Didática, São Paulo, v. 22/23, p. 109-118, 1986/87.

NÉBIAS, Cleide M. O Ciclo básico e a democratização do ensino: do discurso proclamado às representações. 1990. 221f. Tese (Doutorado) - Escola de Comunicações e Artes, Universidade de São Paulo, São Paulo, 1990.

OLIVEIRA, Dalila A. Regulação educacional e trabalho docente: mudanças na gestão dos sistemas e das escolas. In: CONFERÊNCIA INTERNACIONAL EDUCAÇÃO, GLOBALIZAÇÃO E CIDADANIA - NOVAS PERSPECTIVAS DA SOCIOLOGIA DA EDUCAÇÃO. Universidade Federal da Paraíba, International Sociological Association, 2008. v. 1, p. 1-14.

OLIVEIRA, Romualdo P. A Questão da qualidade na educação. Revista Brasileira de Administração da Educação, Brasília, v. 12, n. 1, p. 61-70, jan./jun. 1996.

PARO, Vitor H. Porque os professores reprovam: resultados preliminares de uma pesquisa. Ensaio: Aval. Pol. Educ., Rio de Janeiro, v. 8, n. 28, p. 273-282, 2000.

POPKEWITZ, Thomas S. Reforma educacional: uma política sociológica. Poder e conhecimento em educação. Porto Alegre: Artes Médicas, 1997.

ROMANELLI, Otaíza O. História da educação no Brasil (1930/1973). Petrópolis: Vozes, 1978.

SACRISTÁN, J. Gimeno. O Currículo avaliado. In: . 0 currículo: uma reflexão sobre a prática. Porto Alegre: Artmed, 1998, p. 311-334.

SÃO PAULO. (Estado). Secretaria da Educação. Comunicado SE, 22 mar 1995. Diretrizes Educacionais para o Estado de São Paulo: de janeiro de 1995 a 31 de dezembro de 1998. In: SÃO PAULO (Estado) SE/CENP. Legislação de Ensino de 1ํ e 2º graus; Estadual. São Paulo: SE/CENP, 1995, vol. XXXIX, p. 297-310.

Conselho Estadual de Educação. Deliberação CEE n. 3, 10 de julho de 1991. In: _. Legislação de ensino de $1^{\circ}$ e e $2^{\circ}$ graus. São Paulo: SE/CENP, v. XXXII, 1991. p. 165-169.

Coordenadoria de Estudos e Normas Pedagógicas. Indicação CEE n. 8/97, aprovada em 30 de julho de 1997. Dispõe sobre o regime de progressão continuada. Legislação de ensino fundamental e médio. São Paulo: SE/CENP, 1997. Disponível em: <http://desaocarlos.edunet.sp.gov.br/ Arquivoteca/OT\%2030_3/Documentos/indica\%C3\%A7\%C3\%A30\%20CEE\%20 n\%C2\%BA\%208\%2097.pdf>. Acesso em: 27 fev. 2011.

Coordenadoria de Estudos e Normas Pedagógicas. Parecer CEE n. 67/98, aprovado em 18 de março de 1998. Normas Regimentais Básicas para as Escolas Estaduais. Legislação de ensino fundamental e médio. São Paulo: SEE/CENP, v. XLV, 1998. p. 184-203.

Coordenadoria de Estudos e Normas Pedagógicas. Resolução SE 124. 13 novembro 2001. Dispõe sobre a realização das provas de avaliação dos Ciclos I e II do Ensino Fundamental, nas escolas da rede estadual de ensino, em 2001. Disponível em: <http://siau.edunet.sp.gov.br/ItemLise/ arquivos/124_2001.htm?Time=9/12/2010\%204:31:35\%20AM>. Acesso em: 12 jun. 2010. 
Decreto n. 10.623, de 26 de outubro de 1977. Aprova o Regimento Comum das Escolas Estaduais de $1^{\circ}$ Grau e dá providências correlatas. Disponível em: <http://www.jusbrasil.com.br/legislacao/211193/decreto10623-77-sao-paulo-sp>. Acesso em: 27 fev. 2011.

Descrição das escalas de habilidade do SARESP 96/97/98. Descrição das Escalas de habilidades do SARESP 96/97/98: Línguas Portuguesa e Matemática $-3^{\mathrm{a}}, 4^{\mathrm{a}}$ e $5^{\mathrm{a}}$ séries do Ensino Fundamental, $7^{\mathrm{a}}$ e $8^{\mathrm{a}}$ séries do Ensino Fundamental e $3^{\mathrm{a}}$ série do Ensino Médio, setembro, 1999.

. Modelo pedagógico. São Paulo: SEE, [s/d].

Resolução SE n. 27, de dezembro de 1996. (Deliberação CEE n. 11,

de 11 de dezembro de 1996). In: SÃO PAULO (Estado), Secretaria da Educação. DOE de 28 de dezembro de 1996.

SILVA, Rose N.; DAVIS, Claudia. É proibido repetir. Brasília: MEC, Secretaria da Educação Fundamental, 1994. Série Atualidades Pedagógicas, 4. Disponível em: <http://www.livrosgratis.com.br/arquivos_livros/me002000.pdf>. Acesso em: 21 fev. 2011.

SOBRINHO, J. D. Campos e caminhos da avaliação: a avaliação da educação superior no Brasil. In: FREITAS, L.C. (Org.) Avaliação: construindo o campo e a crítica. Florianópolis: Insular, 2002. p. 13-62.

SOUSA, Sandra M. Z. L. Avaliação da aprendizagem na escola de $1^{\circ}$ grau - legislação, teoria e prática. São Paulo, 1986. Dissertação (Mestrado) Pontifícia Universidade Católica de São Paulo, 1986.

TARDIF, Maurice; LESSARD, Claude (Org.) O Ofício de professor: história, perspectivas e desafios internacionais. 2. ed. São Paulo: Vozes, 2008. 325 p.

SONIA MARIA DUARTE GREGO

Professora adjunta de Departamento de Didática. Orientadora do Programa de Pós-graduação em Educação Escolar da Faculdade de Ciências e Letras do Campus de Araraquara - Unesp. Pós-Doutorado em Avaliação Educacional pela Universidade de Londres. Líder do Grupo de Pesquisa Avaliação e Políticas Educacionais (CNPq) smagrego@fclar.unesp.br 